\title{
Extração de nutrientes e produção de biomassa de aveia-preta cultivada em solo submetido a dezoito anos de adubação orgânica e mineral
}

\section{Nutrient uptake and biomass production of black oats in soils under eighteen years of organic and mineral fertilizer}

\author{
Aurélio Vaz de Melo ${ }^{1 *}$; João Carlos Cardoso Galvão²; Heder Braun ${ }^{3}$; Manoel \\ Mota dos Santos ${ }^{4}$; Ronaldo Rodrigues Coimbra ${ }^{5}$; Rubens Ribeiro da Silva ${ }^{6}$; Willian \\ Fialho dos Reis ${ }^{3}$
}

\begin{abstract}
Resumo
Objetivou-se com este trabalho quantificar a extração de nutrientes e a produção de biomassa de aveiapreta em solos submetidos a dezoito anos de adubações orgânicas e minerais em cultivo de milho. $\mathrm{O}$ experimento foi conduzido no Campo Experimental de Coimbra, localizado no município de Coimbra/ MG, pertencente ao Departamento de Fitotecnia (DFT) da Universidade Federal de Viçosa (UFV). A semeadura da aveia-preta foi realizada no ano agrícola de 2003/2004. Os tratamentos foram: sem adubação; adubação mineral na dose de $150 \mathrm{~kg} \mathrm{ha}^{-1}$ da fórmula 8-28-16 com a adição de $50 \mathrm{~kg} \mathrm{ha}^{-1} \mathrm{de}$ $\mathrm{N}$ em cobertura (AM1); adubação mineral na dose de $300 \mathrm{~kg} \mathrm{ha}^{-1}$ da fórmula 8-28-16 com a adição de $100 \mathrm{~kg} \mathrm{ha}^{-1}$ de N em cobertura (AM2) e adubação orgânica (AO) com $40 \mathrm{~m}^{3} \mathrm{ha}^{-1}$ de composto orgânico. Esses tratamentos foram aplicado sequencialmente no cultivo do milho por um período de dezoito anos. Os tratamentos foram dispostos no delineamento em blocos casualizados, com quatro repetições. Foi determinado o acúmulo de massa seca da parte aérea, teor e acúmulo de $\mathrm{N}, \mathrm{P}, \mathrm{K}$ na parte aérea da aveia preta, teor de P e K no solo, saturação de base e CTC. O tratamento com adubação orgânica proporcionou maior acúmulo de massa seca da parte aérea da aveia-preta e maior extração de nutrientes. Os nutrientes determinados no solo foram diretamente proporcionais aos acúmulos de massa secas e nutrientes determinados na parte aérea da aveia-preta.
\end{abstract}

Palavras-chave: Avena strigosa Schreber. Adubação orgânica. Adubações sucessivas no milho. Reciclagem de nutrientes.

\begin{abstract}
This work aimed to quantify the content and accumulation of macronutrients (N, P and K) in the dry biomass of oats-black (Avena strigosa Schreb) and in soil (P and K), recycled by the oats-black after the waste left in the soil by successive fertilizations organic and mineral carried out in maize. The
\end{abstract}

1 Prof. Adjunto da Área de Ciências Agrárias e Tecnológicas, Universidade Federal do Tocantins, UFT, Gurupi, TO. Cep: 77402970. E-mail: vazdemelo@uft.edu.br

2 Bolsista do CNPq, Prof. Adjunto, Departamento de Fitotecnia, Universidade Federal de Viçosa, UFV, Viçosa, MG. Cep: $36570-$ 000. E-mail: jgalvao@ufv.br

3 Pós-Graduando da Fitotecnia, Eng ${ }^{\mathrm{o}}$ Agr $^{\circ}$, Universidade Federal de Viçosa, UFV, Viçosa, MG. Cep: 36570-000. E-mail: hederbraun@hotmail.com, willianfreis@hotmail.com

4 Prof. Adjunto da Área de Ciências Agrárias e Tecnológicas, Universidade Federal do Tocantins, UFT, Gurupi, TO. Cep: 77402970. E-mail: santosmm@uft.edu.br

5 Prof. Adjunto do curso de Biologia, Universidade Federal do Tocantins, UFT, Porto Nacional, TO. Cep: 77500-000. E-mail: ronaldo.rc@uft.edu.br

6 Prof. Adjunto do curso de Agronomia, Universidade Federal do Tocantins, UFT, Gurupi, TO Cep: 77402-970. E-mail: rrs2002@ uft.edu.br

* Autor para correspondência 
experiment was conducted at the Experimental Field of Coimbra, located in the city of Coimbra / MG from the Department of Plant Science (DFT) of the Federal University of Viçosa (UFV). The planting of oats-black was conducted in the agricultural year 2003/2004. The treatments were: no fertilization, mineral fertilization at $150 \mathrm{~kg} \mathrm{ha}^{-1}$ of 8-28-16 formulation with the addition of $50 \mathrm{~kg} \mathrm{ha}^{-1} \mathrm{~N}$ topdressing (AM1); mineral fertilization at $300 \mathrm{~kg} \mathrm{ha}^{-1}$ of 8-28-16 formulation with the addition of $100 \mathrm{~kg} \mathrm{ha}^{-1} \mathrm{~N}$ topdressing (AM2) and organic manure (AO) with $40 \mathrm{~m}^{3}$ ha $^{-1}$ of compost. These treatments were applied sequentially in corn cultivation for a period of eighteen. The treatments were arranged in a randomized block design with four replications. Was determined the accumulation of dry mass of aerial part, content and accumulation of N, P and K in shoots of oats-black, P and K content in soil, base saturation and CTC. The treatment with organic fertilization provided higher accumulation of dry matter of aerial part of oats-black and nutrient uptake. The nutrients determined in the soil were directly proportional to the accumulation of dry mass and specific nutrients in shoots of oats-black.

Key words: Avena strigosa Schreber. Organic fertilization. Successive manurings in the corn. Nutrients recycling.

\section{Introdução}

A aveia-preta é uma das principais plantas utilizadas pelos produtores com a finalidade de formação de cobertura do solo. Dentre as principais vantagens do cultivo da aveia-preta destacam-se: ciclagem de nutrientes, mobilização de cátions no perfil do solo (SPAGNOLLO, 2000; AMADO; MIELNICZUK, 2000) bem como modificações químicas no perfil do solo que aumentam a disponibilidade de nutrientes. Essas vantagens proporcionam benefícios ao solo e às culturas comerciais cultivadas em sucessões.

Segundo Floss (2002), os restos vegetais das gramíneas são fornecedoras de nutrientes, a médio e longo prazo, às culturas sucessoras, com acúmulo na camada superficial. Este processo, segundo o autor favorece o aumento nos teores de fósforo $(\mathrm{P}) \mathrm{e}$ potássio (K) do solo sob o sistema de plantio direto. Bortolini, Silva e Argenta (2000) e Calegari (2001) relataram que a aveia-peta é eficiente na reciclagem de nutrientes, apresenta baixa taxa de decomposição dos resíduos comparado às fabáceas, em função da alta relação $\mathrm{C} / \mathrm{N}(>30)$.

No caso do nitrogênio $(\mathrm{N})$, que é um elemento muito móvel no sistema, estima-se que 60 a $70 \%$ desse nutriente encontrado na biomassa das plantas são reciclados e novamente absorvido pelas plantas no cultivo seguinte (SPAIN; SALINAS, 1985). As saídas ou perdas desse mineral ocorrem via perdas por volatilização, lixiviação, percolação e escorrimento por erosão laminar.

A disponibilidade de $\mathrm{N}$ estimula $\mathrm{o}$ desenvolvimento e a atividade radicular, incrementa a absorção de outros nutrientes (YANAI et al., 1996) e a quantidade de massa seca produzida pela aveia (SANTI, 2001). Na aveia-preta, o N é o nutriente que tem maior efeito no crescimento e que, freqüentemente, na ausência limita sua produção de massa verde.

A produção de massa seca de aveia obtida no experimento conduzido por Crusciol et al. (2008) foi de $2.953 \mathrm{~kg} \mathrm{ha}^{-1}$. Em relação a massa seca da aveia depositada sobre o solo, Calegari (1990) constatou a concentração de $\mathrm{N}, \mathrm{P}$ e K de $16,5 \mathrm{~g} \mathrm{~kg}^{-1} ; 1,0 \mathrm{~g} \mathrm{~kg}^{-1}$ e $16 \mathrm{~g} \mathrm{~kg}^{-1}$, respectivamente. Da mesma forma, a aveia-preta extrai os nutrientes das camadas mais profundas do solo, por meio do sistema radicular, disponibilizando-os superficialmente, após o corte da parte aérea e a decomposição pela ação dos microorganismos. Crusciol et al. (2008), relataram que o acúmulo de $\mathrm{N}, \mathrm{P}$ e $\mathrm{K}$ foi, respectivamente, de $70,1 \mathrm{~kg} \mathrm{ha}^{-1}, 14,7 \mathrm{~kg} \mathrm{ha}^{-1}$ e $88,4 \mathrm{~kg} \mathrm{ha}^{-1}$.

Os recentes aumentos nos preços dos insumos agrícolas fizeram com que os agricultores voltassem sua atenção para a adoção da prática vegetativa e o uso de resíduos para o manejo da fertilidade e da cobertura do solo. O uso de plantas de cobertura, embora não substitua a adubação mineral, pode ser uma forma de complementação (SCHREINER, 1988; PHILIPOVSKY; MEDRADO; DEDECEK, 
1997). Além disso, o uso esterco bovino na fertilização do solo pode proporcionar regularização na disponibilidade dos nutrientes e favorecer maior produtividade das culturas.

Assim, a aveia-preta por apresentar grande acúmulo de matéria seca e extração de nutrientes, pode ser usada para disponibilizar nutrientes às culturas que serão implantadas após seu cultivo, além de manter a cobertura do solo. Na literatura ainda são poucas as informações que enfatizam a extração de nutrientes em solos submetidos a fertilizações orgânicas e minerais em cultivos de milho.

Desta forma, objetivou-se com este trabalho quantificar a extração de nutrientes e a produção de biomassa de aveia-preta em solos submetidos a dezoito anos de adubações orgânicas e minerais em cultivo de milho.

\section{Material e Métodos}

O experimento foi conduzido no Campo Experimental de Coimbra, localizado no município de Coimbra - MG, na latitude 20 51'24' sul e na longitude $42^{\circ} 48^{\prime} 10^{\prime \prime}$ oeste e na altitude de $720 \mathrm{~m}$, pertencente ao Departamento de Fitotecnia (DFT) da Universidade Federal de Viçosa (UFV).

O solo da área foi classificado como Argissolo Vermelho-Amarelo Câmbico, fase terraço (Embrapa, 1999). Antes da instalação do experimento, características químicas e granulométricas foram determinadas pela análise de amostras das camadas de $0-20 \mathrm{~cm}$ de profundidade. $\mathrm{O}$ solo apresenta textura média, com 22; 29; 49 dag $\mathrm{kg}^{-1}$ de areia, silte e argila, respectivamente. As características químicas foram as seguintes: $\mathrm{pH}$ em água de 5,2; 1,36 $\mathrm{cmol}_{\mathrm{c}} \mathrm{dm}^{3}$ de $\mathrm{Ca} ; 0,45 \mathrm{cmol}_{\mathrm{c}} \mathrm{dm}^{3}$ de $\mathrm{Mg} ; 0,40$ $\mathrm{cmol}_{\mathrm{c}} \mathrm{dm}^{3}$ de Al; 1,99 $\mathrm{cmol}_{\mathrm{c}} \mathrm{dm}^{3}$ de soma de bases; 2,39 CTC efetiva (t); 4,65 $\mathrm{cmol}_{\mathrm{c}} \mathrm{dm}^{3}$ de CTC a pH 7,0; 13,37 mg dm de P; 70,18 mg dm $^{3}$ de K; 42,79\% de saturação de base e 3,2\% de matéria orgânica.

Nos anos antecedentes ao experimento da aveia- preta a área vinha sendo cultivada no sistema de plantio direto com a cultura do milho desde o ano agrícola de 1984/1985. Foram aproveitadas as parcelas do experimento onde cultivou-se milho por safras sucessivas para conduzir o experimento da aveia-preta em sistema de plantio direto.

Os dados climáticos médios referentes ao período em que o experimento da aveia-preta permaneceu instalado no campo foram: temperatura de $17,8{ }^{\circ} \mathrm{C}$, umidade relativa de $86 \%$ e precipitação total do período de $92,4 \mathrm{~mm}$.

Durante o cultivo contínuo de milho por dezoito anos, os tratamentos foram constituídos, conforme segue: sem adubação; adubação mineral na dose de $150 \mathrm{~kg} \mathrm{ha}^{-1}$ da fórmula 8-28-16 com a adição de $50 \mathrm{~kg} \mathrm{ha}^{-1}$ de $\mathrm{N}$ em cobertura (AM1); adubação mineral na dose de $300 \mathrm{~kg} \mathrm{ha}^{-1}$ da fórmula 8-2816 com a adição de $100 \mathrm{~kg} \mathrm{ha}^{-1}$ de $\mathrm{N}$ em cobertura (AM2) e adubação orgânica (AO) com $40 \mathrm{~m} 3$ ha $^{-1}$ de composto orgânico, cuja composição foi : $\mathrm{pH}=$ 6,57, 1,03 dag $\mathrm{kg}^{-1}$ de N, 2 dag $\mathrm{kg}^{-1}$ de P, 0,4 dag $\mathrm{kg}^{-1}$ de K, 2,63 dag $\mathrm{kg}^{-1}$ de Ca, 0,59 dag $\mathrm{kg}^{-1}$ de $\mathrm{Mg}$, 51,8 $\mathrm{mg} \mathrm{kg}^{-1}$ de $\mathrm{Cu}, 285,0 \mathrm{mg} \mathrm{kg}^{-1}$ de Zn, 45,1 mg $\mathrm{kg}^{-1}$ de Mn e $9176 \mathrm{mg} \mathrm{kg}^{-1}$ de Fe e relação $\mathrm{C} / \mathrm{N}$ de 13,32. Nos tratamentos que receberam adubações nitrogenadas em cobertura foi utilizada a uréia como fonte de N. O experimento foi instalado sob o delineamento de blocos casualizados com quatro repetições.

A semeadura da aveia-preta foi realizada com máquina de plantio direto empregando-se 36 sementes viáveis por metro linear, no dia 22 de julho 2003. As parcelas foram constituídas de 40 linhas de $8 \mathrm{~m}$ de comprimento, espaçadas de $0,20 \mathrm{~m}$ entre si. As duas linhas laterais e $0,5 \mathrm{~m}$ das extremidades das linhas centrais serviram como bordadura, para fins de amostragem, totalizando $56,25 \mathrm{~m}^{2}$ de área útil.

O controle de plantas daninhas foi realizado, quando necessário, com capina manual, movimentando apenas a camada superficial do solo, de forma a destruir as plantas daninhas emergidas e as que estavam em estádio de germinação. 
Foi realizada a roçada da aveia-preta a $5 \mathrm{~cm}$ do solo, no dia 22 de outubro de 2003, utilizando-se uma ceifadeira motorizada, coincidindo com a época de enchimento de grão. A massa seca da parte aérea foi determinada no estádio de grão leitoso, com duas amostragens ao acaso dentro da área útil da parcela, com um quadro de $0,09 \mathrm{~m}^{2}$ de área. A parte aérea da aveia-preta coletada foi colocada em estufa a $70^{\circ} \mathrm{C}$ até atingir massa constante. Após, as amostras foram pesadas para determinação da massa seca.

Após a pesagem, procedeu-se à moagem das amostras em moinho tipo Wiley, equipado com peneira 40 mesh (diâmetro de 0,45 mm). Em seguida, uma sub-amostra do material moído foi digerida em acido sulfúrico concentrado. Após a digestão, a amostra foi analisada quanto ao teor de N-NO3 sendo determinado por espectrofotometria, no comprimento de onda $210 \mathrm{~nm}$ (CAWSE, 1967). Em outra sub-amostra de $0,5 \mathrm{~g}$ de massa seca da parte aérea da aveia-preta foi submetida à digestão nítrico perclórica para determinação de fósforo $(\mathrm{P})$ e potássio (K). O K foi dosado em espectrofotômetro de chama e o P em espectrofotômetro, a 725 nm (BRAGA; DEFELIPO, 1974). O acúmulo dos nutrientes na parte aérea foi obtido pela multiplicação do teor do nutriente pela produtividade de massa seca da aveia- preta.

Para realizar a análise química do solo, foram coletadas amostras de solo três meses antes da semeadura da aveia-preta na profundidade de 0-20 $\mathrm{cm}$, com trado de rosca, retirando 10 amostras simples, formando-se uma amostra composta em cada parcela. Após a coleta, as amostras foram encaminhadas ao laboratório e secas ao ar. Em seguida foram determinados os teores de $\mathrm{P}$ e $\mathrm{K}$, soma de base (SB) e capacidade de troca cátions (CTC a $\mathrm{pH} 7,0$ ) em cada parcela.

Os dados foram submetidos a análise de variância e as médias comparadas pelo teste de Tukey, a 5\% de probabilidade. Os dados foram também submetidos à análise de correlação linear simples (r). Para análise dos dados foi utilizando o Aplicativo Computacional em Genética e Estatística - Programa Genes versão Windows (CRUZ, 2001).

\section{Resultados e Discussão}

Para todas as características analisadas, os valores referentes ao teste $\mathrm{F}$, seus respectivos valores de probabilidade, bem como o coeficiente de variação são apresentados na (Tabela 1).

Tabela 1. Resumo do teste F com seus respectivos valores de probabilidade (p), coeficiente de variação (CV), desvio médio significativo (DMS) e média geral dos dados da análise de variância para as características: acúmulo de massa seca (AMS), acúmulo de nitrogênio (AN- PA), acúmulo de fósforo (AP- PA), acúmulo de potássio (AK- PA) na parte aérea e teor de fósforo (TP-S), teor de potássio (TK-S), soma de base (SB) e capacidade de troca catiônica (CTC) no solo

\begin{tabular}{lllll}
\hline Parâmetros & Tratamento & CV \% & DMS & Média geral \\
\hline AMS (kg ha-1) & $46,82(\mathrm{p}<0,001)$ & 23,59 & 1313,54 & 2518,7 \\
AN- PA (kg ha-1) & $23,49(\mathrm{p}<0,001)$ & 35,46 & 18,99 & 24,2 \\
AP- PA (kg ha-1) & $14,98(\mathrm{p}<0,001)$ & 41,95 & 6,79 & 7,3 \\
AK- PA (kg ha-1) & $39,00(\mathrm{p}<0,001)$ & 25,67 & 28,09 & 49,5 \\
TP-S (kg ha-1) & $9,69(\mathrm{p}<0,001)$ & 51,21 & 11,39 & 10,1 \\
TK-S (kg ha-1) & $79,00(\mathrm{p}<0,001)$ & 14,38 & 57,38 & 180,5 \\
SB (cmolc dm-3) & $48,69(\mathrm{p}<0,001)$ & 13,62 & 0,81 & 2,72 \\
CTC (cmolc dm-3) & $6,01(\mathrm{p}=0,015)$ & 11,02 & 1,31 & 5,39 \\
\hline
\end{tabular}


Houve efeito significativo dos tratamentos para todas as características analisadas na parte aérea da aveia-preta (Tabela 2). Para o acúmulo de P na parte aérea (AP-PA) não houve diferenças estatísticas entre os tratamentos com adubação mineral. O tratamento com adubação orgânica (AO) proporcionou as maiores médias de acúmulo de massa seca (AMS), teores de $\mathrm{N}, \mathrm{P}$ e $\mathrm{K}$ na parte aérea, diferindo-se estatisticamente dos demais tratamentos.

Tabela 2. Acúmulo de massa seca (AMS), acúmulo de nitrogênio (AN-PA), acúmulo de fósforo (AP- PA), acúmulo de potássio (AK- PA) na parte aérea (PA) e teor de fósforo (TP-S), teor de potássio (TK-S), soma de base (SB) e capacidade de troca catiônica (CTC) no solo (S), Coimbra, MG.

\begin{tabular}{|c|c|c|c|c|c|}
\hline & Tratamentos & AMS & AN- PA & AP- PA & AK- PA \\
\hline & & \multicolumn{4}{|c|}{ 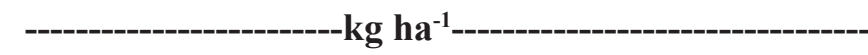 } \\
\hline \multirow[t]{6}{*}{ Parte aérea } & Sem adubação & $602,78 \mathrm{C}$ & $5,55 \mathrm{C}$ & $1,75 \mathrm{~B}$ & $12,06 \mathrm{C}$ \\
\hline & AM1 & $1299,98 \mathrm{C}$ & $11,31 \mathrm{BC}$ & $4,06 \mathrm{~B}$ & $25,71 \mathrm{C}$ \\
\hline & AM2 & $3005,55 \mathrm{~B}$ & $28,06 \mathrm{~B}$ & $8,18 \mathrm{~B}$ & $59,21 \mathrm{~B}$ \\
\hline & AO & $5166,67 \mathrm{~A}$ & $51,99 \mathrm{~A}$ & $15,31 \mathrm{~A}$ & $101,14 \mathrm{~A}$ \\
\hline & & TP-S & TK-S & SB & CTC \\
\hline & & \multicolumn{2}{|c|}{--------'mg dm'-------- } & \multicolumn{2}{|c|}{------cmolc dm'--------- } \\
\hline \multirow[t]{4}{*}{ Solo } & Sem adubação & $2,25 \mathrm{~B}$ & $115,25 \mathrm{~B}$ & $2,47 \mathrm{~B}$ & $5,00 \mathrm{~B}$ \\
\hline & AM1 & $6,00 \mathrm{~B}$ & $120,18 \mathrm{~B}$ & $1,96 \mathrm{~B}$ & $5,26 \mathrm{AB}$ \\
\hline & AM2 & $11,25 \mathrm{AB}$ & $133,50 \mathrm{~B}$ & $1,84 \mathrm{~B}$ & $4,85 \mathrm{~B}$ \\
\hline & AO & $20,75 \mathrm{~A}$ & $353,25 \mathrm{~A}$ & $4,62 \mathrm{~A}$ & $6,45 \mathrm{~A}$ \\
\hline
\end{tabular}

Médias seguidas pelas mesmas letras maiúsculas na coluna não diferem estatisticamente entre si pelo teste de Tukey, a $5 \%$ de probabilidade.

O rendimento médio da AMS de aveia-preta variou de 602,78 a $5.166,67 \mathrm{~kg} \mathrm{ha}^{-1}$, sendo a menor quantidade de AMS obtida no tratamento que não recebeu adubação e a maior para o tratamento que recebeu AO. No tratamento sem adubação, a produção de matéria seca foi $88 \%$ menor daquela produzida no tratamento com AO (Tabela 2). Este resultado evidencia que o $\mathrm{N}$ fornecido pela mineralização da matéria orgânica desse solo não foi suficiente para maximizar a produção de matéria seca da parte aérea da aveia-preta. Dentre os tratamentos que receberam adubação mineral (AM1 e AM2), o tratamento AM2 apresentou AMS da ordem de $57 \%$ maior que o tratamento AM1. Provavelmente, esse efeito foi devido à dose de 100 $\mathrm{kg} \mathrm{ha}^{-1}$ de $\mathrm{N}$ aplicado em cobertura. No entanto, a aplicação da dose de $100 \mathrm{~kg} \mathrm{ha}^{-1} \mathrm{~N}$ em cobertura mostrou-se satisfatória para a produção matéria seca da aveia-preta, como planta de cobertura do solo. O rendimento de AMS obtido está próximo dos valores encontrados por Calegari (1990), para aveia-preta, no sul do Paraná, que relatou amplitude de 4,7 a $7,3 \mathrm{tha}^{-1}$.

Camargo e Piza (2007) relataram maior produtividade de matéria seca da aveia-preta $(3,49$ $\left.\mathrm{t} \mathrm{ha}^{-1}\right)$ em relação à aveia-branca $\left(2,58 \mathrm{t} \mathrm{ha}^{-1}\right)$, nabo forrageiro $\left(2,56 \mathrm{t} \mathrm{ha}^{-1}\right)$, braquiária $\left(1,98 \mathrm{t} \mathrm{ha}^{-1}\right) \mathrm{e}$ testemunha (correspondente a área em pousio, 0,67 $\mathrm{t} \mathrm{ha}^{-1}$ ). De acordo com os relatos de Floss (2002), a aveia-preta se destaca dentre as culturas de inverno em maior produção de matéria seca para formação de palhada que será utilizada pela cultura em sucessão.

Os dados referentes ao acúmulo de $\mathrm{N}$ na parte aérea (AN-PA) da aveia-preta indicam que, embora não seja uma planta leguminosa, acumula e recicla 
o $\mathrm{N}$, segundo nutriente de maior quantidade na biomassa seca da parte aérea da aveia-preta (Tabela $2)$. Esse fato também foi verificado por Borkert et al. (2003) e Guimarães (2000) avaliando o efeito de rotações de culturas no verão (milho e soja), com uso da área no inverno com as culturas feijão, milheto, mucuna, braquiária e pousio, observou que o acúmulo de $\mathrm{N}$ nesses materiais foram 58,6, $70,6,64,6,62,4$ e $60,3 \mathrm{~kg} \mathrm{ha}^{-1}$, respectivamente. Os resultados do pressente experimento estão inferiores ao encontrado por Moraes (2001), em solos de cerrado, obtendo valores de $126,7 \mathrm{~kg} \mathrm{ha}^{-1}$ de $\mathrm{N}$ na matéria seca de aveia-preta. Segundo Borkert et al. (2003) o N é o segundo nutriente de maior quantidade na massa após o $\mathrm{K}$, tendo encontrado nos seis intervalos de classe de rendimento de matéria seca, uma amplitude média observada de 59 a 224 $\mathrm{kg} \mathrm{ha}^{-1}$ e 100 a $507 \mathrm{~kg} \mathrm{ha}^{-1}$. O maior conteúdo de $\mathrm{N}$ na matéria seca $\left(51,99 \mathrm{~kg} \mathrm{ha}^{-1}\right)$ foi obtido no tratamento com adubação orgânica (AO). Isso significa que parte da dose de $\mathrm{N}$ aplicada na cultura do milho foi disponibilizada para a cultura da aveia-preta, pois, de acordo com Spain e Salinas (1985), cerca de 70\% de $\mathrm{N}\left(30\right.$ a $\left.187 \mathrm{~kg} \mathrm{ha}^{-1}\right)$ poderá ser disponibilizado para a cultura seguinte. A reciclagem de $\mathrm{N}$ por meio da sucessão de cultivo possibilita uma dinâmica desse nutriente em frações e formas orgânicas mais facilmente decomponíveis.

Para o acúmulo de $\mathrm{P}$ na parte aérea (AP-PA), o tratamento com AO resultou em maior acúmulo de P (15,31 kg ha-1 de P) (Tabela 2), sendo que os demais tratamento não diferiram significativamente entre si. O tratamento com $\mathrm{AO}$ acumulou $88 \%$ a mais em relação ao tratamento sem adubação.

Dentre os macronutrientes, o $\mathrm{P}$ é reciclado em menor quantidade pela aveia-preta, variando de 8 a $12 \mathrm{~kg} \mathrm{ha}^{-1}$, no intervalo de classe variando de $5 \mathrm{a}$ $10 \mathrm{t} \mathrm{ha}^{-1}$ de matéria seca (BORKERT et al., 2003). Contudo, no presente trabalho o acúmulo de $\mathrm{P}$ foi superior aos valores observados na literatura. Comportamento semelhante foi observado por Giacomini et al. (2003) trabalhando com aveiapreta, ervilhaca, nabo e pousio em cultivo isolado e consorciado, em 1998, 1999 e 2000, relataram que a aveia acumulou na matéria seca cerca de 16,13 e $12 \mathrm{~kg} \mathrm{ha}^{-1}$ de $\mathrm{P}$, respectivamente.

Dentre os nutrientes estudados, o $\mathrm{K}$ foi, quantitativamente, o mais ciclado pela aveia-preta, alcançando, somente na parte aérea, 101,14 kg ha-1 de $\mathrm{K}$, no tratamento que recebeu AO. Giacomini et al. (2003) relataram que a quantidade de $\mathrm{K}$ acumulado pela gramínea aveia-preta foi maior do que a da leguminosa ervilhaca em apenas 19\%, em 1999, e $53 \%$, em 2000, e não diferiu do ano de 1998. A reciclagem de K pela aveia é uma importante estratégia de redução de perdas por lixiviação na entressafra de culturas comerciais (SANTI; AMADO; ACOSTA, 2003). A aveia-preta pode servir como recicladora de $\mathrm{K}$, por possuir sistema radicular profundo, permitindo retornar para a camada superficial do solo o K lixiviado para subcamadas (BORKERT et al., 2003).

Para o teor de P (TP-S) e K (TK-S) no solo foram observadas diferenças significativas entre os tratamentos. Para o TK-S não houve diferença entre os tratamentos com adubação mineral e o controle (Tabela 2). A palha que é adicionada ao solo sofre decomposição pelos microrganismos e ocorre a mineralização dos elementos que compõem o material orgânico, liberando-os para o solo. Com isso, quanto maior a quantidade de matéria seca produzida pela aveia preta é maior o teor de nutrientes liberados à solução do solo.

O tratamento com $\mathrm{AO}$ proporcionou os melhores resultados, atingindo valores relativamente satisfatórios quanto ao TP-S e TK-S. A utilização de AO é uma das alternativas de maior receptividade pelos agricultores, pois quando adequadamente manejados, aumentam a fertilidade do solo, principalmente o teor dos nutrientes $\mathrm{P}$ e K, diminuem o potencial poluidor, tornando-se um importante fator agregador de valor, já que é um recurso natural disponível nas propriedades, sendo capaz de promover maior estabilidade econômica, social e ambiental. 
Houve correlação significativa $(\mathrm{P}<0,01)$ entre todas as características avaliadas. A produção de matéria seca da aveia correlacionou-se positivamente com todos os parâmetros estudados, com exceção do teor de P (TP-PA) e K na parte aérea (TK-PA) (Tabela 3). Com relação às correlações entre os resultados das análises de solo com os teores de $\mathrm{N}, \mathrm{P}$ e K na parte aérea da aveia-preta, houve correlação significativa e negativa apenas para o TP-S com o TPPA $(r=-0,50)$ e com TK-S $(r=-0,23)$; TK-PA com TP-S $(r=-0,85)$ e com TK-S $(r=-0,67)$. Maiores
TK-S proporcionaram menores TK-PA, atingindo coeficiente de correlação de $(r=-0,67)$. O oposto ocorreu para o acúmulo de $\mathrm{K}$ na parte aérea em relação ao TK-S, com coeficiente de correlação de ( $\mathrm{r}$ $=0,89)$ (Tabela 3). Tecchio et al. (2006) trabalhando com Niagara Rosada (Videira), relataram que o teor de $\mathrm{K}$ no solo é diretamente proporcional aumento no teor de $\mathrm{K}$ na folha de videira. No entanto, os resultados estão contraditórios aos de Dal-Bó et al. (1989) que relataram correlação positiva entre teor de $\mathrm{K}$ no solo com teor de $\mathrm{K}$ na folha de videira.

Tabela 3. Coeficientes de correlações entre características: acúmulo de massa seca (AMS), teor de nitrogênio (TN-PA), acúmulo de nitrogênio (AN-PA), teor de fósforo (TP-PA), acúmulo de fósforo (AP- PA), teor de potássio (TK- PA), acúmulo de potássio (AK- PA) da parte aérea e teor de fósforo (TP-S), teor de potássio (TK-S), Coimbra, MG

\begin{tabular}{|c|c|c|c|c|c|c|c|c|}
\hline Parâmetros & TN- PA & AN- PA & TP- PA & AP- PA & TK- PA & AK- PA & TP-S & TK-S \\
\hline AMS & $0,72 * *$ & $0,99 * *$ & $-0,56^{* *}$ & $0,99 * *$ & $-0,83^{* *}$ & $0,99 * *$ & $0,99 * *$ & $0,89 * *$ \\
\hline TN-PA & & $0,74 * *$ & $-0,54 * *$ & $0,71 * *$ & $-0,22 * *$ & $0,72 * *$ & $0,69 * *$ & $0,79 * *$ \\
\hline AN-PA & & & $-0,54 * *$ & $0,99 * *$ & $0,81 * *$ & $0,99 * *$ & $0,99 * *$ & $0,91 * *$ \\
\hline TP- PA & & & & $-0,51 * *$ & $0,26 * *$ & $-0,57 * *$ & $-0,50 * *$ & $-0,23 * *$ \\
\hline AP- PA & & & & & $-0,84 * *$ & $0,99 * *$ & $0,99 * *$ & $0,91 * *$ \\
\hline TK- PA & & & & & & $-0,83 * *$ & $-0,85^{* *}$ & $-0,67 * *$ \\
\hline $\mathrm{AK}-\mathrm{PA}$ & & & & & & & $0,99 * *$ & $0,89 * *$ \\
\hline TP-S & & & & & & & & $0,90 * *$ \\
\hline
\end{tabular}

** significativo, a 1\% de probabilidade pelo teste 't' na correlação de Pearson.

O P é o nutriente mais limitante da produtividade de biomassa em plantas cultivadas em solos tropicais (NOVAIS; SMYTH, 1999). Houve correlação altamente significativa $(\mathrm{P}<0,01)$ entre o TP-S com o AN-PA bem como o AP-PA, atingindo coeficiente de correlação de $(r=0,99)$ para as duas relações especificadas. Desse modo, é indicada uma interação positiva entre N e P. Prado, Romualdo e Vale (2006) relataram que a maior absorção de P na presença de $\mathrm{N}$ seria causada pelo envolvimento de $\mathrm{N}$ nos processos de absorção e de transporte interno de P.

Observou-se alto coeficiente de correlação dos resultados da análise do solo com os dados dos nutrientes na parte aérea o que se deve provavelmente a influência dos fatores nutricionais na produção de matéria seca e reciclagem de nutrientes.

A aveia-preta pode ser uma alternativa de cultura antecessora ao cultivo do milho. Por possuir nos resíduos deixados sobre o solo maior acúmulo de $\mathrm{N}, \mathrm{P}$ e K para ciclagem no solo, indicando menor período de imobilização e maior disponibilidade de $\mathrm{N}$ para o milho em sucessão, além da alta produção de palhada para cobertura do solo. Sá (1997) constatou, em cultivo sucessivo da aveia-preta/ milho, o mesmo resultado que a aplicação de $\mathrm{N}$ na 
semeadura do milho.

Os resultados encontrados demonstram o elevado potencial de ciclagem de nutrientes pela aveia-preta, quando o requerimento de $\mathrm{N}$ é atendido. Com isto, ressalta-se a importância da adubação nitrogenada na aveia em situações de baixa disponibilidade de $\mathrm{N}$, comum na fase de implantação do sistema plantio direto ou em sucessões de gramíneas.

\section{Conclusões}

O uso da adubação orgânica proporciona maior reciclagem de nutrientes e produção de matéria seca no cultivo sucessional da aveia preta em relação o uso da adubação mineral.

\section{Agradecimentos}

Registra-se aqui os melhores agradecimentos ao CNPq pela concessão das Bolsas de Pesquisa que muito auxiliou na realização de nossas pesquisas.

\section{Referências}

AMADO, T. J. C.; MIELNICZUK, J. Estimativa da adubação nitrogenada para o milho em sistemas de manejo e culturas de cobertura do solo. Revista Brasileira de Ciência do Solo, Viçosa, v. 24, n. 3, p. 553-560, 2000.

BORKERT, C. M.; GAUDÊNCIO, C. A.; PEREIRA, J. E.; PEREIRA, L. R.; OLIVEIRA JUNIOR, A. Nutrientes minerais na biomassa da parte aérea em culturas de cobertura de solo. Pesquisa Agropecuária Brasileira, Brasília, v. 38, n. 1, p. 143-153, jan. 2003.

BORTOLINI, C. G.; SILVA, P. R. F.; ARGENTA, G. Efeito de resíduos de plantas jovens de aveia preta em cobertura de solo no crescimento inicial do milho. Pesquisa Agropecuária Gaúcha, Porto Alegre, v. 6, n. 1, p. 83-88, 2000.

BRAGA, J. M.; DEFELIPO, B. Determinação espectrofotométrica de fósforo em extratos de solos e plantas. Revista Ceres, Viçosa, v. 21, n. 113, p. 73-85, 1974.

CALEGARI, A. Plantas para adubação verde de inverno no sudoeste do Paraná. Londrina: Instituto Agronômico do Paraná, 1990. 37 p. (Boletim Técnico, 35).
CALEGARI, A. Rotação de culturas e plantas de cobertura como sustentáculo do sistema de plantio direto. In: CONGRESSO BRASILEIRO DE CIÊNCIA DO SOLO, 18., Londrina, 2001. Anais... Londrina: Sociedade Brasileira de Ciência do Solo, 2001. p. 241.

CAMARGO, R.; PIZA, R. J. Produção de biomassa de plantas de cobertura e efeitos na cultura do milho sob sistema plantio direto no município de passos, $M G$. Bioscience Journal, Uberlândia, v. 23, n. 3, p. 76-80, july./sept. 2007.

CAWSE, P. A. The determination of nitrate in soil solution by ultraviolet spectrophotometry. Analyst, v. 9, p. 309-313, 1967.

CRUSCIOL, C. A. C.; MORO, E.; LIMA, E. V.; ANDREOTTI, M. Taxas de decomposição e de liberação de macronutrientes da palhada de aveia preta em plantio direto. Bragantia, São Paulo, v. 67, n. 2, p. 261-266, 2008.

CRUZ, C. D. Programa GENES: aplicativo computacional em genética e estatística versão Windows. Viçosa, MG. UFV, 2001. 442 p.

DAL-BÓ, M. A.; BECKER, M.; BASSO, C.; STUKER, H. Levantamento do estado nutricional da videira em Santa Catarina por análise de solo e tecido. Revista Brasileira de Ciência do Solo, Viçosa, v. 13, n. 4, p. 335340, 1989.

FLOSS, E. L. Aveia, um sustentáculo do sistema de semeadura direta. Revista Plantio Direto, Passos Fundo, v. 72, n. 69, p. 14-18, 2002.

GIACOMINI, S. J.; AITA, C.; VENDRUSCOLO, E. R. O.; CUBILlA, M.; NICOLOSO, R. S.; FRIES, M. R. M. Matéria seca, relação $\mathrm{C} / \mathrm{N}$ e acúmulo de nitrogênio, fósforo e potássio em misturas de plantas de cobertura de solo. Revista Brasileira de Ciência do Solo, Viçosa, v. 27, n. 2, p. 325-334, 2003.

GUIMARÃES, G. L. Efeitos de culturas de inverno e do pousio na rotação de culturas de soja e do milho em sistema de plantio direto. 2000. (Mestrado em Fitotecnia) - Universidade Estadual Paulista, Ilha Solteira.

MORAES, R. N. S. Decomposição das palhadas de sorgo e milheto, mineralização de nutrientes e seus efeitos no solo e na cultura do milho em plantio direto. 2001. (Mestrado em Solos). Universidade Federal de Lavras, Lavras.

PHILIPOVSKY, J. F.; MEDRADO, M. J. S.; DEDECEK, R. A. Avaliação de diferentes coberturas do solo no inverno para a associação com a cultura da erva mate no municipio de Ponta Grossa, PR. Colombo: Embrapa, 1997. p. 1-5. (Pesquisas em Andamento, 30). 
SÁ, J.C. de M. Manejo do nitrogênio na cultura do milho no sistema plantio direto. In: SIMPÓSIO DA CULTURA DO MILHO, 1., 1997, Piracicaba. Resumos. Piracicaba: ESALQ, 1997. p. 84-103.

SANTI, A. Adubação nitrogenada na aveia preta (Avena strigosa, Schieb): decomposição da fitomassa, liberação de nitrogênio e rendimento do milho em sucessão. 2001. (Mestrado em Fitotecnia) - Universidade Federal de Santa Maria, Santa Maria.

SANTI, A.; AMADO, T. J. C.; ACOSTA, J. A. A. Adubação nitrogenada na aveia preta. I - Influência na produção de matéria seca e ciclagem de nutrientes sob sistema plantio direto. Revista Brasileira de Ciência do Solo, Viçosa, v. 27, n. 6, p. 1075-1083, 2003.

SCHREINER, H. G. Associação de leguminosas com plantios florestais para cobertura e melhoramento do solo. Boletim de Pesquisa Florestal, Colombo, v. 1, n. 17, p. 1-12, 1988.

SPAGNOLLO, E. Plantas de cobertura intercalares ao milho em sistemas de cultivo mínimo e convencional. 2000. Tese (Mestrado em Fitotecnia) Universidade do Estado de Santa Catarina, Lages.

SPAIN, J. M.; SALINAS, J. G. A reciclagem de nutrientes nas pastagens tropicais. In: REUNIÃO BRASILEIRA DE FERTILIDADE DO SOLO, 16., 1985, Ilhéus. Anais... Ilhéus: Comissão Executiva do Plano da Lavoura Cacaueira, 1985. p. 259-299.

TECCHIO, M. A.; PIRES, E. J. P.; TERRA, M. M.; GRASSI FILHO, H.; CORREAA, J. C.; VIEIRA, C. R. Y. I. Correlação entre a produtividade e os resultados de análise foliar e de solo em vinhedos de niagara rosada. Revista Ciência e Agrotecnologia, Lavras, v. 30, n. 6, p. 1056-1064, nov./dez. 2006.

YANAI, J.; LINEHAN, D. J.; ROBINSON, D.; YOUNG, I. M.; HACKETT, C. A.; KYUMA, K.; KOSAKI, T. Effects of inorganic nitrogen application on the dynamics of the soil solution composition in the root zone of maize. Plant and Soil, v. 180, n. 1, p. 1-9, 1996. 
Melo, A. V. et al. 